\title{
Smoking reduction and the rate of decline in FEV1: results from the Lung Health Study
}

\author{
M.S. Simmons*, J.E. Connett ${ }^{\#}$, M.A. Nides ${ }^{\ddagger}$, P.G. Lindgren", E.C. Kleerup*, \\ R.P. Murray ${ }^{+}$, W.M. Bjornson ${ }^{\S}$ and D.P. Tashkin*
}

\begin{abstract}
Previous findings from the Lung Health Study have shown that smoking cessation and sustained abstinence substantially reduce the rate of decline in forced expiratory volume (FEV1) among smokers with early chronic obstructive pulmonary disease (COPD) when compared with continuing smoking. Intermittent quitters demonstrated rates of FEV1 decline intermediate between those of sustained quitters and continuing smokers.

In this study, data from 1,980 participants were analysed from 10 centres of the Lung Health Study in the USA and Canada. All participants were smokers with mild-to-moderate COPD who were unable to quit smoking at any time during the 1st yr of the study.

No linear relationship was found between reduction in cigarettes per day and changes in FEV 1 during the 1st yr of the study. However, examination of the data revealed that this relationship was nonlinear. Further analysis found that smokers who reduced their cigarettes per day to very low amounts had smaller declines in FEV 1 than those who did not. Reduction in cigarettes per day was associated with only minimal changes in the presence of chronic respiratory symptoms.

In conclusion, compensatory changes in smoking behaviour may account for the limited and unpredictable impact of smoking reduction on lung function decline and symptom prevalence when compared with smoking cessation.
\end{abstract}

KEYWORDS: Forced expiratory volume in one second, smoking cessation, smoking reduction

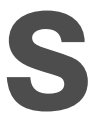
ustained smoking cessation substantially reduces the smoking-related accelerated rate of decline in forced expiratory volume in one second (FEV1) and decreases the frequency of chronic respiratory symptoms among smokers with early chronic obstructive pulmonary disease (COPD) when compared with continuing smokers [1-3]. Intermittent quitting is associated with rates of FEV1 decline intermediate between those observed in sustained quitters and continuing smokers [4]. Conversely, it is not known whether partial reduction in the number of cigarettes smoked per day among continuing smokers is associated with improvement in the subsequent course of lung function decline when compared with that observed when daily consumption remains unchanged. For smokers with COPD who find it difficult to quit smoking entirely this is an important issue, since they may assume that smoking reduction is an effective alternative strategy for slowing disease progression. In the only previous long-term prospective study of smoking reduction (from $\geqslant 15$ to $<15$ cigarettes $\cdot$ day $^{-1}$ ) on the rate of FEV1 decline, smokers $<55$ yrs showed a significant reduction in FEV1 decline, although older smokers did not [5]. In that study, only two measurements of lung function were performed at an interval of $5 \mathrm{yrs}$ and details of changes in the smoking rate, including the timing of changes in smoking amount relative to the measurement of lung function, were not reported.

The present analysis examines the relationship between smoking reduction and change in FEV1 in a subset of the participants in the Lung Health Study, a large, multicentre smoking cessation study [6]. This subset consisted of 1,980 continuing smokers with mild-to-moderate COPD who were unable to quit smoking at any time during the 1st yr of the study.

\section{METHODS}

The Lung Health Study enrolled 5,887 participants (3,702 male, 2,185 female; age 35-60 yrs) with mild-to-moderate COPD, at 10 centres in the USA and Canada, in a 5-yr study of the effect of intensive smoking cessation counselling and maintenance therapy with an inhaled bronchodilator on the annual change in lung function [1].

Participants were randomly assigned to special intervention (SI) and usual care (UC) groups. SI participants $(n=3,923)$ were entered into an intensive smoking cessation programme [7]. SI
AFFILIATIONS

*David Geffen School of Medicine, University of California (UCLA), and "Los Angeles Clinical Trials, Los Angeles, $\mathrm{CA}$

\#Division of Biostatistics, University of Minnesota School of Public Health, Minneapolis, MN, and ${ }^{\S}$ Oregon Health Sciences University, Portland, OR, USA.

${ }^{+}$Dept of Community Health Sciences, University of Manitoba, Winnipeg, Canada.

CORRESPONDENCE M.S. Simmons

Division of Pulmonary and Critical Care Medicine

David Geffen School of Medicine at UCLA

Los Angeles

CA 90095-1690

USA

Fax: 13102065088

E-mail: msimm@ucla.edu

Received:

July 232004

Accepted after revision:

February 222005

\section{SUPPORT STATEMENT}

This research is supported by contracts N01 HR 46002 and N01 HR 46016 from the Division of Lung Diseases, National Heart, Lung and Blood Institute, National Institutes of Health (Bethesda, MD, USA). Boehringer Ingelheim Pharmaceuticals, Inc. (Ridgefield, CT, USA) supplied Atrovent and placebo inhalers. 
participants were also randomised to receive either an ipratropium bromide metered-dose inhaler (18 mg.puff ${ }^{-1}$, Atrovent ${ }^{\mathrm{TM}}$; Boehringer Ingelheim, Ridgefield, CT, USA) or an identically appearing placebo inhaler. Participants were told to take two puffs from the inhaler three times daily. UC participants $(n=1,964)$ were referred to their personal physicians and community smoking cessation programmes. As inhaled ipratropium was shown to have an acute effect on lung function [1], and, therefore, could affect the delivery of tobacco smoke to the lung, the 1,961 SI participants receiving active ipratropium have been excluded from the present analysis.

Participants were followed for 5 yrs with annual clinic followup visits for assessment of smoking status and lung function. Follow-up spirometry was conducted on 89 and $94 \%$ of the participants at year 1 and year 5, respectively. Participants were asked at each annual visit how many cigarettes per day they were smoking on average at the time of the visit and during each of the previous 12 months. This analysis of continuing smokers is restricted to data from the first annual visit and includes only participants who reported no period of abstinence from smoking during each of the intervening 12 months. For analysis, smoking amount was based on participant self-reports of cigarettes per day smoked at the time of the first annual visit. End-expired carbon monoxide (CO) measurements were performed at the annual visit to confirm smoking status. Salivary cotinine (relatively stable metabolite of nicotine) measurements were performed, but the resulting data appeared to have systematic measurement errors which precluded their use. Participants were asked to refrain from smoking for $\geqslant 2 \mathrm{~h}$ prior to visiting the clinic to avoid affecting the pulmonary function tests.

\section{Statistical analysis}

The relationship between change in the rate of decline of FEV1 and per cent change in cigarettes per day during the 1st yr of the study was investigated by analysis of covariance. Baseline descriptors were included in the model as covariates including: group assignment (SI/UC); age; FEV1 per cent predicted; pack-years of cigarette smoking; per cent improvement in FEV1 following two puffs of $100 \mu \mathrm{g}$ isoproterenol; the twopoint slope of the methacholine dose-response relationship; presence of chronic respiratory symptoms at baseline (cough and/or sputum); and per cent change in weight from baseline to the first annual visit [8]. Males and females were analysed both together and separately. Various univariate and multivariate models were developed to investigate the relationships between the dependent variable (change in FEV1) and the covariates, and to identify significant covariates to be included in a final model. Smoothed spline curves were fitted to the data to inspect for nonlinear effects.

Analysis of covariance was also performed using change in smoking amount as a threshold rather than as a continuous variable. Continuing smokers were categorised according to whether or not they had reduced their smoking amount below the threshold value at the end of the 1st yr of study. The variables included in this model were the same as those used in the analysis of covariance of smoking changes described above.

The relationship between changes in chronic pulmonary symptoms and per cent change in cigarette smoking rate during the 1st yr of the study was examined using logistic regression. Baseline variables included in the model as independent variables included age, sex, cigarettes per day and FEV1 as per cent predicted. Separate analyses were performed for each symptom: chronic cough, sputum production, cough productive of sputum, wheezing and shortness of breath. The relationship between annual changes in end-expired $\mathrm{CO}$ and cigarettes per day was examined by linear regression.

A significance level of $p<0.05$ was used for all statistical tests and all tests were two-tailed.

\section{RESULTS}

In the 1st yr of the study, 1,999 out of 3,926 (50.9\%) UC and SI (placebo inhaler) participants were continuing smokers. Analysable data were obtained from 1,980 participants (733 female, 1,247 male; 506 SI, 1,474 UC). Baseline characteristics are given in table 1 . Reductions of $>10 \%$ in smoking rate after $1 \mathrm{yr}$ were observed in $50 \%$ of continuing smokers $(21 \%$ reduced $11-25 \%$; $20 \% 26-50 \%$; $5 \% 51-75 \%$; and $3 \%$ reduced by $>75 \%)$. Smoking rate was essentially unchanged $(<10 \%$ change in either direction) in $37 \%$ of participants and smoking rate increased by $>10 \%$ in $13 \%$ of participants.

Analysis of covariance of year 1 data found no statistically significant relationship between annual per cent change in cigarettes per day and change in FEV1. The analysis controlled for age, pack-years of cigarette smoking, baseline FEV1, group assignment, bronchodilator response, the two-point slope of the methacholine response curve, the presence of chronic respiratory symptoms at baseline (cough and/or sputum) and per cent change in weight from baseline to the first annual visit. However, examination of spline-curve fitted plots of the observed data (fig. 1) suggests that: 1) the apparent relationship is nonlinear; 2) most of the observed decline occurs in those participants who had large per cent reductions in cigarette smoking; and 3) only negligible effects were observed among those with $<\sim 60 \%$ reduction in their smoking rate.

\begin{tabular}{|c|c|c|}
\hline & Male & Female \\
\hline Subjects $n$ & 1247 & 733 \\
\hline Group assignment SI/UC & $309 / 938$ & $197 / 536$ \\
\hline Age yrs & $48.3 \pm 6.9$ & $48.3 \pm 6.6$ \\
\hline Height $\mathbf{c m}$ & $176.6 \pm 6.5$ & $163.7 \pm 5.9$ \\
\hline Weight kg & $81.8 \pm 13.0$ & $65.2 \pm 11.5$ \\
\hline Body mass index & $26.2 \pm 3.7$ & $24.3 \pm 4.0$ \\
\hline FEV1 L pre-bronchodilator & $2.96 \pm 0.44$ & $2.08 \pm 0.35$ \\
\hline FEV $1 \%$ pred pre-bronchodilator & $75.3 \pm 8.7$ & $74.9 \pm 9.0$ \\
\hline Change in FEV $1 \%$ pre-bronchodilator & $4.1 \pm 4.9$ & $4.2 \pm 5.3$ \\
\hline $\begin{array}{l}\text { Two-point slope of methacholine } \\
\text { curve }\end{array}$ & $-9.8 \pm 21.5$ & $-18.6 \pm 29.2$ \\
\hline Cigarettes per day & $33.6 \pm 13.2$ & $29.7 \pm 11.5$ \\
\hline Pack-yrs & $43.3 \pm 19.3$ & $36.9 \pm 17.6$ \\
\hline \multicolumn{3}{|c|}{$\begin{array}{l}\text { Data are presented as mean } \pm \mathrm{SD} \text {, unless otherwise stated. SI: specia } \\
\text { intervention; UC: usual care; } F E V 1 \text { : forced expiratory volume in one second } \\
\text { pred: predicted. }\end{array}$} \\
\hline
\end{tabular}




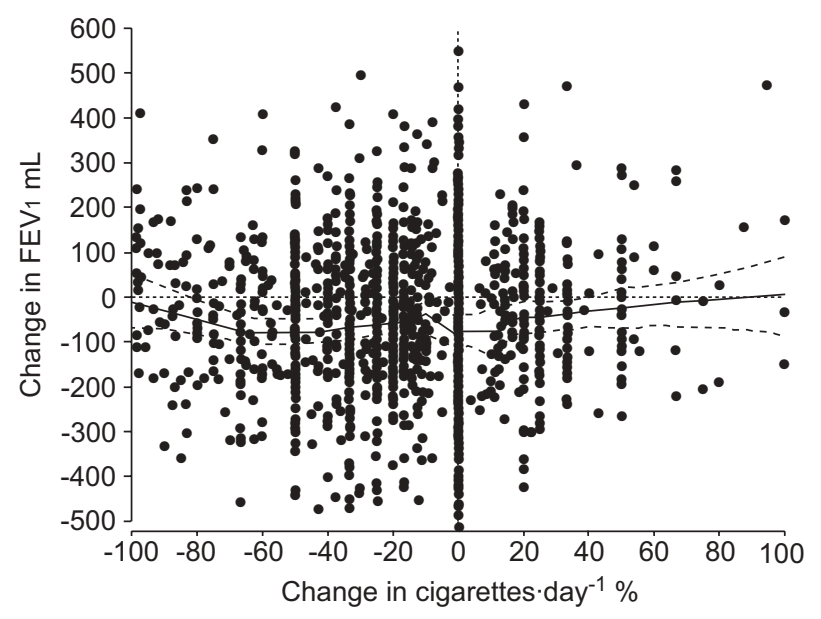

FIGURE 1. Change in forced expiratory volume in one second (FEV1) among continuing smokers versus change in cigarettes per day during the 1 st $y r$ of the Lung Health Study. A spline curve (-) is fitted to the data along with the $95 \%$ confidence limits (- - - ).

Furthermore, the variability around the plotted curve is extremely high (95\% confidence interval -267.0-208.1 mL). Thus, the use of a linear model with these data is questionable. The relationship between change in FEV1 during the 1st yr of the study and a nonlinear function of change in smoking amount over the same interval was examined using multiple linear regression, but no statistically significant relationship was found.

The means of change in FEV1 during the 1st yr of the study, by categories of change in cigarettes per day, are presented in figure 2. Categories of change in cigarettes per day were chosen to examine the nature of the relationship between change in FEV1 and smoking reduction among continuing smokers who had the greatest reduction in smoking amount. It is among these continuing smokers that the relationship

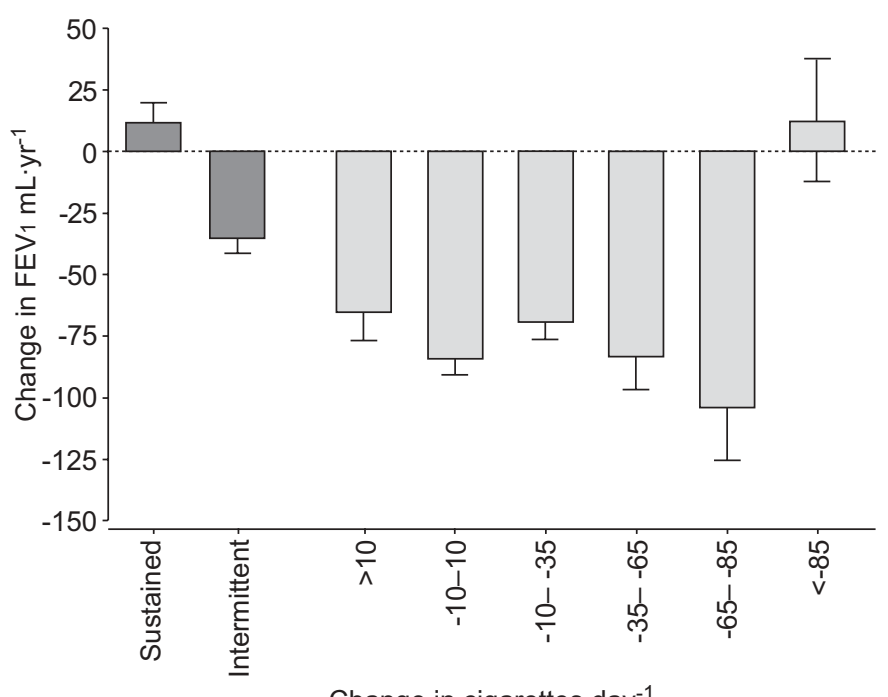

FIGURE 2. Change in forced expiratory volume in one second (FEV1) for sustained and intermittent quitters $(\square)$ and continuing smokers $(\square)$ with various degrees of smoking reduction during the 1st yr of the Lung Health Study. deviates from linearity in figure 1 , and the rate of decline in FEV1 appears most likely to be influenced by reduction in smoking amount. The 1-yr means for sustained and intermittent quitters are also shown for comparison. All continuing smokers demonstrated declines in FEV1, except for those who achieved the greatest reduction in cigarette smoking rate of $\geqslant 85 \%$. The latter small $(n=39)$ group of smokers demonstrated a net increase in FEV1 during the year that was similar to that of the completely abstinent group (sustained quitters). This rebound phenomenon has previously been described among sustained quitters in the Lung Health Study [3]. All other groups of continuing smokers, regardless of the presence or degree of smoking reduction, suffered a continued decline in FEV1 at rates similar to one another and to those previously reported for continuing smokers overall [3]. Thus, only those smokers whose reductions in cigarette smoking were particularly striking $(>85 \%)$ appear to have received any benefit, as measured by change in FEV1. The decline in FEV1 among intermittent quitters was less than in all groups of continuing smokers except those who had reduced by the greatest amount. It is noteworthy that only $2 \%$ (39 out of 1,980) of continuing smokers in this study reported this level of reduction after $1 \mathrm{yr}$.

Longitudinal analysis was performed using all data from the last 5 yrs with a model incorporating both random and fixed effects. This effort was complicated by the variety of changes in smoking behaviour and patterns observed in different years. For example, because the smoking rate at the first follow-up visit provides the starting point for change during the $2 \mathrm{nd} \mathrm{yr}$, 2nd-yr changes include striking increases in those who reduced smoking substantially during the 1st yr and returned to baseline during the 2nd yr. Furthermore, few continuing smokers changed their smoking behaviour during the later years of the study and, thus, little is gained by adding those data to the analysis. Due to these difficulties, the results of the longitudinal analysis using data from all 5 yrs were unclear and difficult to interpret. Consequently, this method of analysis was not pursued further.

To determine if compensatory changes in smoking behaviour (e.g. increases in puff volume or number of puffs) in response to a reduction in the number of cigarettes smoked might be responsible for the nonlinear nature of the relationship apparent in figure 1, the effect of reduction in smoking to a sufficiently low level that complete compensation would be unlikely to occur was examined. Using analysis of covariance, changes in FEV1 of continuing smokers who had reduced their smoking amount to or below a low threshold value (i.e. 10, 5 or 3 cigarettes $\cdot$ day $^{-1}$ ) were compared with changes in FEV1 among those who had not reduced below that level. The same covariates were used as in the previous analyses described above, and analyses were performed for males and females separately. No difference was noted between those above and below the 10 cigarette $\cdot$ day $^{-1}$ threshold among either males or females. Conversely, females who reduced their smoking amount to $\leqslant 5$ cigarettes $\cdot$ day $^{-1}$ had significantly less decline in FEV1 after 1 yr than those who still smoked $>5$ cigarettes daily $(p=0.0047)$. Moreover, both females and males who declined to $\leqslant 3$ cigarettes $\cdot$ day $^{-1}$ had significantly less decline in FEV1 than those who did not $(p=0.0045$ and $p=0.0211$, respectively). These data are presented in figure 3 . 

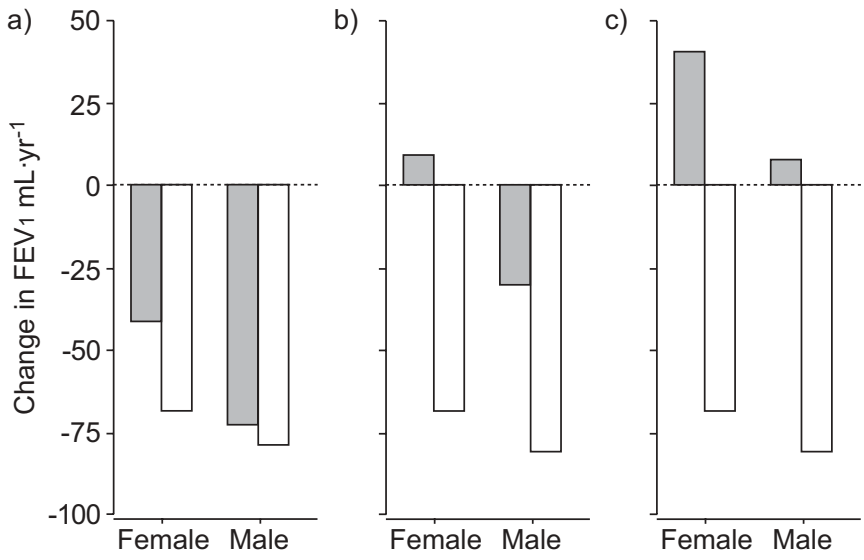

FIGURE 3. Change in forced expiratory volume in one second (FEV 1$)$ for continuing smokers who either changed cigarettes per day smoked to threshold or less $(\square)$ or greater than threshold $(\square)$, by sex, during the 1st yr of the Lung Health

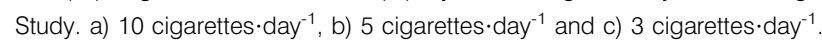

Annual changes in end-expired $\mathrm{CO}$ measurements and cigarettes per day were compared by regression analysis in males and females separately to determine if compensatory changes in smoking technique might have occurred; if complete compensation occurred, no change in $\mathrm{CO}$ level would be observed in relation to smoking reduction. Results of this analysis revealed that $\mathrm{CO}$ levels did decline with reductions in cigarettes per day, but the effect was very small. A reduction of $25 \%$ in cigarettes per day during the 1 st $\mathrm{yr}$ of the study was associated with a decline of only $2.8 \%$ in endexpired $\mathrm{CO}$ in females and $3.1 \%$ in males. The change in cigarettes per day explained $<1 \%$ of the variance of the change in CO level over the 1st yr, although the lack of a significant relationship could be due to the high variability of end-expired $\mathrm{CO}$ measurements. These data are presented in figure 4 . The number of participants included in this analysis $(n=607)$ is less than the number in the pulmonary function analysis because baseline $\mathrm{CO}$ measurements were not performed in some participants at some study centres.

Changes in mean body weight for each category of change in smoking amount represented in figure 2 (continuing smokers only) are given in table 2 by sex. Most categories of continuing smokers gained weight over the 1st yr, but the changes were generally small. Those whose smoking rates decreased by $65-$ $85 \%$ gained the most weight on average. All categories of continuing smokers except one had mean weight gains significantly smaller than those of both the sustained and intermittent quitters. This finding is consistent with compensatory changes in smoking behaviour that limit actual nicotine delivery to the lung despite reductions in the number of cigarettes smoked per day.

The relationship between the change in cigarette smoking amount and the gain or loss of chronic pulmonary symptoms during the 1st yr of the study was examined using logistic regression. The odds ratios for gaining or losing each symptom following a $25 \%$ reduction in cigarette smoking rate are given in table 3. Statistically significant relationships were observed for only two out of the 10 possible changes in chronic
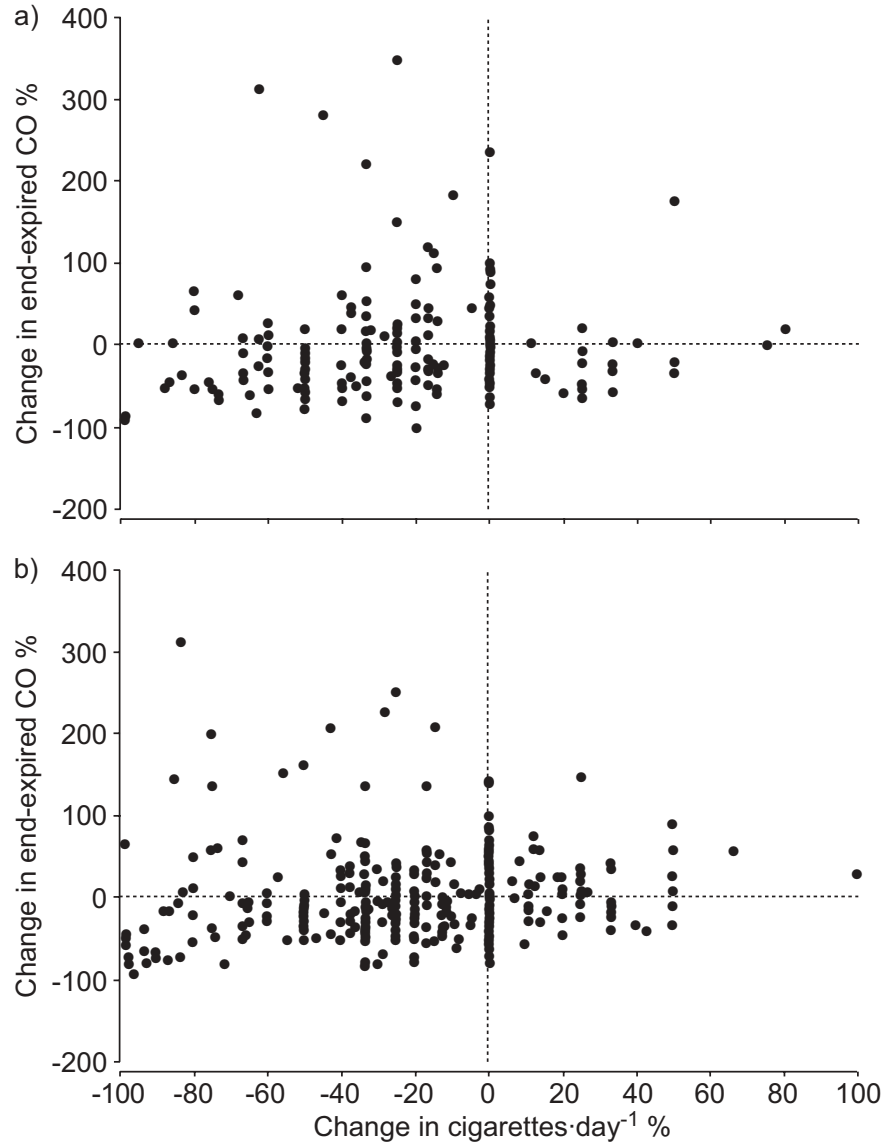

FIGURE 4. Change in end-expired carbon monoxide (CO) versus change in cigarettes per day among continuing smokers after 1 yr of the Lung Health Study for a) females, and b) males.

respiratory symptoms tested. Among those participants who had reported sputum production at the baseline visit, decreasing cigarette smoking rate was associated with a loss of the symptom. Increased cigarette smoking was associated

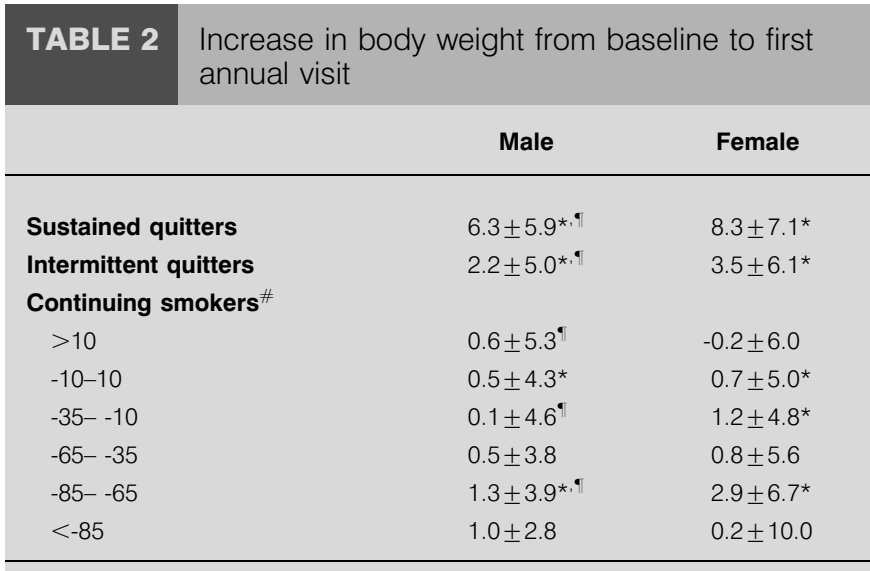

Data are presented as mean \pm SD. ${ }^{\#}$ : values represent per cent change in cigarettes per day. *: significant increase from baseline, $\mathrm{p}<0.05$, t-test; $\bullet$ significant difference from females, $p<0.05$, t-test. 


\begin{tabular}{|c|c|c|c|c|c|c|c|c|}
\hline \multirow[t]{3}{*}{ TABLE 3} & $\begin{array}{l}\text { ving chro } \\
\text { veen bas }\end{array}$ & $\begin{array}{l}\text { respirat } \\
\text { ne and th }\end{array}$ & $\begin{array}{l}\text { ymptc } \\
\text { st anr }\end{array}$ & $\begin{array}{l}\text { at the time } \\
\text { visit }\end{array}$ & fhe first & nual visit & wing a & decrease in \\
\hline & \multicolumn{4}{|c|}{ Participants with the symptoms at baseline } & \multicolumn{4}{|c|}{ Participants without the symptoms at baseline } \\
\hline & Baseline & Retained & OR & $95 \% \mathrm{Cl}$ & Baseline & Gained & OR & $95 \% \mathrm{Cl}$ \\
\hline Cough & $859(43)$ & $667(78)$ & 0.90 & $0.79-1.04$ & $1117(57)$ & $348(31)$ & $0.92^{*}$ & $0.85-1.00$ \\
\hline Phlegm & $736(37)$ & $514(70)$ & $0.83^{*}$ & $0.79-1.04$ & $1240(63)$ & $323(26)$ & 0.97 & $0.90-1.05$ \\
\hline Increased cough and phlegm ${ }^{\#}$ & $580(29)$ & $390(67)$ & 0.87 & $0.75-1.01$ & $1396(71)$ & $314(22)$ & 0.96 & $0.88-1.04$ \\
\hline Wheeze & $1511(76)$ & $1270(84)$ & 0.92 & $0.82-1.03$ & $465(24)$ & $141(30)$ & 0.97 & $0.87-1.07$ \\
\hline Shortness of breath & $841(43)$ & $570(68)$ & 0.99 & $0.90-1.10$ & 1096 (57) & $235(21)$ & 0.94 & $0.85-1.04$ \\
\hline
\end{tabular}

with a report of cough at the first annual visit among those who had denied cough at baseline.

\section{DISCUSSION}

Linear analyses did not find a relationship between reduction in smoking amount and reduction in the rate of decline in FEV1 in continuing smokers with mild-to-moderate COPD enrolled in the Lung Health Study. However, a nonlinear effect was apparent when the data were examined both graphically and analytically. Very large reductions in smoking amount (e.g. $>60 \%$ ) appeared to reduce the rate of FEV1 decline, but there were few smokers who reduced their smoking amount to this extent without quitting smoking completely, and very large variability was observed within this small subset. Reductions of up to $50 \%$ in smoking amount had no observable effect on the decline in FEV1 among either males or females. In previous studies, participants in the Lung Health Study who quit smoking prior to the first 4-month follow-up visit and, subsequently, remained abstinent (sustained quitters) exhibited a significant increase in FEV1 during the 1st yr after smoking cessation, followed by a steady decline comparable to that reported for never-smokers [1, 3]. Among smokers who achieved intermittent periods of complete smoking abstinence but at other times maintained their regular smoking habit (intermittent quitters), the annual rate of decline in FEV1 was intermediate between that of sustained quitters and continuing smokers who did not have periods of abstinence [3,4].

It should be noted that the Lung Health Study was not a study of smoking reduction, but rather one of smoking cessation in which smokers in the SI group were encouraged and assisted in the goal of quitting smoking entirely. By contrast, reduced smoking (either as an intermediate step toward complete cessation or as a final goal) was not, as a rule, discussed with the participants. Participants were entered into the study only after expressing a desire to quit smoking completely, although some participants may have subsequently and independently pursued a strategy of smoking reduction rather than complete cessation.

Smokers who reduce the number of cigarettes smoked per day often demonstrate changes in smoking topography (e.g. increased puff volume and/or number of puffs per cigarette) in an unconscious attempt at self-titration of nicotine, apparently driven by a physiological need to maintain nicotine levels [9-11]. Similar compensatory smoking behaviour has been observed in smokers who switch from high- to lownicotine/tar cigarettes [12-16]. The lack of a significant reduction in the rate of FEV1 decline with moderate reductions in smoking amount could be due to compensation, although smoking behaviour was not directly measured in the Lung Health Study. The relatively small changes observed in endexpired $\mathrm{CO}$ compared to correspondingly larger reductions in cigarette smoking suggest the possibility of compensatory smoking behaviour, but this finding could also be due, at least in part, to the high variability of end-expired $\mathrm{CO}$ caused by its short half-life. The lack of significant changes in weight among continuing smokers compared to quitters is also consistent with small changes in actual nicotine delivery to the lungs despite changes in smoking amount.

Compensatory changes in smoking behaviour following smoking reduction can be attenuated by nicotine replacement therapy or pharmacological aids that reduce nicotine craving, such as bupropion $[17,18]$. In a study conducted by JIMENEZRuIz et al. [18] five out of 12 severe COPD patients demonstrated improvement in respiratory symptoms and pulmonary function after reducing smoking from $>30$ cigarettes day $^{-1}$ to an average of 6 cigarettes $\cdot$ day $^{-1}$, with the aid of nicotine replacement therapy. An association has also been demonstrated between nicotine gum use and smoking reduction in both the Lung Health Study [19] and a report by WENNIKE et al. [20].

Even with the free availability of nicotine replacement therapy in the Lung Health Study, a very large reduction in the number of cigarettes smoked per day (probably to $<5$ cigarettes $\cdot$ day $^{-1}$ in this group of moderately heavy smokers) appeared to be necessary in order to significantly affect the annual rate of decline in FEV1. Presumably, at such a low threshold of smoking amount, the smokers were no longer able to compensate for the reduced intake of nicotine by changing their smoking technique. While moderate smoking reduction has been shown to be achievable and sustainable, both in the Lung Health Study [19] and other studies [11], reduction $<5$ cigarettes $\cdot$ day $^{-1}$ among formerly heavy smokers has proven to be an elusive goal even with nicotine replacement therapy [21]. In practice, therefore, it appears that only complete abstinence 
from smoking provides an obtainable goal that is likely to lead to a predictable and meaningful clinical benefit, as measured by changes in the rate of decline in FEV1 in moderately heavy smokers with mild-to-moderate airflow limitation.

A limitation of the present analysis is that it is based on selfreported reductions in smoking that could have been exaggerated in the highly motivated participants in the Lung Health Study. Those in the SI group, in particular, may have been anxious to please the study staff who had provided intensive counselling and encouragement. Assessment of cigarette smoke exposure by direct measurement of cotinine could address these potential sources of error. Unfortunately, the measurements of salivary cotinine obtained during the Lung Health Study exhibited significant unexplained variability between annual visits which precluded their use in this analysis. Another limitation is that, although those who reported quitting smoking completely at any time during the 1st yr were excluded from the analysis, self-reported smoking rate at the annual visit may not have been representative of smoking rate throughout the entire year.

Lung Health Study participants who quit smoking but occasionally relapsed (intermittent quitters) showed significant improvement in their rate of lung function decline (i.e. less decline) when compared with continuing smokers, but less improvement than sustained quitters [4]. MURRAY et al. [4] found that these intermittent quitters suffered less loss of lung function than continuing smokers who smoked similar cumulative numbers of cigarettes over the $5 \mathrm{yrs}$. The latter findings and the results of the present analysis suggest that a clinically meaningful reduction in the effect of tobacco smoke on lung function generally cannot be achieved without periods of total abstinence from smoking. The reason for this is unclear. It is possible that complete quitting allows smoking-related inflammatory changes to resolve between relapses, with a net beneficial effect on lung function. The constant irritant effect of toxic smoke components from continued smoking may sustain the inflammatory process, even with greatly reduced smoke exposure. Whether significant improvement in the rate of decline in lung function might be achieved by very large, sustained reductions in smoking remains an unanswered question; such reduction appears to be rare and generally unsustainable.

Substantial levels of smoking reduction were found to be associated with significant reductions in phlegm production, but not other chronic pulmonary symptoms. Improvements in chronic respiratory symptoms have been associated with smoking cessation in Lung Health Study participants [2] and with reduction in smoking amount to very low levels in patients with severe COPD [18]. Whereas smoking cessation in heavy smokers ( $\geqslant 15$ cigarettes $\cdot$ day $^{-1}$ ) participating in three prospective Danish population studies was associated with a significant reduction in the risk of hospitalisation for COPD when compared with continuing heavy smoking, reduction in smoking by $\geqslant 50 \%$ without quitting was not [22]. It appears that substantial reduction in smoking amount may reduce mucous hypersecretion even when the reduction is insufficient to terminate the injurious process that leads to progressive airways dysfunction. Conversely, RENNARD et al. [17] noted decreased lower respiratory tract inflammation by endoscopic visualisation of the airway mucosa and bronchoalveolar lavage in previously heavy smokers who partially reduced smoking concomitant with nicotine replacement therapy.

In view of the present findings of only minimal benefit from sustainable levels of smoking reduction in modifying the rate of loss of lung function, it is advisable for health professionals to continue to counsel patients toward an ultimate goal of complete smoking cessation. It must be noted, however, that research continues into other potential health benefits of smoking reduction, including reduced risks of cardiovascular complications and of lung and upper aerodigestive tract cancer $[23,24]$. The role of smoking reduction in promoting eventual smoking cessation (the best method of harm reduction) is still uncertain [11, 19, 20, 25-27]. While smokers who are unable or unwilling to quit may derive limited benefit from partial smoking reduction, complete smoking cessation remains a necessity for those wanting to minimise all of the harmful effects of smoking.

\section{ACKNOWLEDGEMENTS}

The authors would like to thank the principal investigators and senior staff of the clinical and coordinating centres, the NHLBI, members of the Safety and Data Monitoring Board, and the Morbidity and Mortality Review Board, as follows. Case Western Reserve University, Cleveland, OH, USA: M.D. Altose (Principal Investigator), A.F. Connors (Co-Principal Investigator), S. Redline (Co-Principal Investigator), C.D. Deitz, R.F. Rakos; Henry Ford Hospital, Detroit, MI, USA: W.A. Conway Jr (Principal Investigator), M. Eichenhorn (Principal Investigator), A. DeHorn (Co-Principal Investigator), J.C. Ward (former Co-Principal Investigator), C.S. Hoppe-Ryan, R.L. Jentons, J.A. Reddick, C. Sawicki; Johns Hopkins University School of Medicine, Baltimore, MD, USA: R.A. Wise (Principal Investigator), S. Permutt (Co-Principal Investigator), C.S. Rand (Co-Principal Investigator); Mayo Clinic, Rochester, MN, USA: P.D. Scanlon (Principal Investigator), L.J. Davis (Co-Principal Investigator), R.D. Hurt (Co-Principal Investigator), R.D. Miller (Co-Principal Investigator), D.E. Williams (Co-Principal Investigator), G.M. Caron, G.G. Lauger, S.M. Toogood (Pulmonary Function Quality Control Manager); Oregon Health Sciences University, Portland, OR, USA: A.S. Buist (Principal Investigator), W.M. Bjornson (Co-Principal Investigator), L.R. Johnson (LHS Pulmonary Function Coordinator); University of Alabama at Birmingham, AL, USA: W.C. Bailey (Principal Investigator and Associate Chief of Staff for Education, Department of Veterans Affairs Medical Center, Birmingham), C.M. Brooks (Co-Principal Investigator), J.J. Dolce, D.M. Higgins, M.A. Johnson, B.A. Martin; University of California, LA, USA: D.P. Tashkin (Principal Investigator), A.H. Coulson (Co-Principal Investigator), H. Gong (former CoPrincipal Investigator), P.I. Harber (Co-Principal Investigator), V.C. Li (Co-Principal Investigator), M.A. Nides, M.S. Simmons, I.P. Zuniga; University of Manitoba, Winnipeg, Canada: N.R. Anthonisen (Principal Investigator, Steering Committee Chair), J. Manfreda (Co-Principal Investigator), R.P. Murray (CoPrincipal Investigator), S.C. Rempel-Rossum, J.M. Stoyko; University of Minnesota Coordinating Center, MN, USA: J.E. Connett, PhD (Principal Investigator), M.O. Kjelsberg (CoPrincipal Investigator), M.K. Cowles, D.A. Durkin, P.L. Enright, K.J. Kurnow, W.W. Lee, P.G. Lindgren, S. Mongin, 
P. O'Hara (LHS Intervention Coordinator), H.T. Voelker, L. Waller; University of Pittsburgh, Pittsburgh, PA, USA: G.R. Owens $^{\dagger}$ (Principal Investigator), R.M. Rogers (Principal Investigator), J.J. Johnston, F.P. Pope, F.M. Vitale; University of Utah, Salt Lake City, UT, USA: R.E. Kanner (Principal Investigator), M.A. Rigdon (Co-Principal Investigator), K.C. Benton, P.M. Grant (the Salt Lake City Center has been assisted by the Clinical Research Center, Public Health Research Grant M01-RR00064 from the National Center for Research Resources); Safety and Data Monitoring Board: M. Becklake, B. Burrows ${ }^{\dagger}$, P. Cleary, P. Kimbel ${ }^{\dagger}$ (Chairperson), L. Nett (former member), J.K. Ockene, R.M. Senior (Chairperson), G.L. Snider, W. Spitzer (former member), O.D. Williams; National Heart, Lung and Blood Institute Staff, Bethesda, MD, USA: S.S. Hurd (Former Director, Division of Lung Diseases), J.P. Kiley (Former Project Officer and Director, Division of Lung Diseases), M.C. Wu (Division of Epidemiology \& Clinical Applications); Mortality and Morbidity Review Board: S.M. Ayres, R.E. Hyatt, B.A. Mason.

\section{REFERENCES}

1 Anthonisen NR, Connett JE, Kiley JP, et al. Effects of an inhaled anticholinergic bronchodilator on the rate of decline in FEV1. JAMA 1994; 272: 1497-1505.

2 Kanner RE, Connett JE, Williams DE. Buist AS for the Lung Health Study Research Group. Effects of randomized assignment to a smoking cessation intervention and changes in smoking habits on respiratory symptoms in smokers with early chronic obstructive pulmonary disease: the Lung Health Study. Am J Med 1999; 106: 410-416.

3 Scanlon PD, Connett JE, Waller LA, et al. Smoking cessation and lung function in mild-to-moderate chronic obstructive pulmonary disease. Am J Respir Crit Care Med 2000; 161: 381-390.

4 Murray RP, Anthonisen NR, Connett JE, et al. Effects of multiple attempts to quit smoking and relapses to smoking on pulmonary function. J Clin Epidemiol 1998; 51: 1317-1326.

5 Lange P, Groth S, Nyboe GJ, et al. Effects of smoking and changes in smoking habits on the decline of FEV1. Eur Respir J 1989; 2: 811-816.

6 Tashkin DP, Nides MA, Simmons MS, Kleerup EC, Connett JE, Lindren P. Does partial reduction in smoking affect the annual rate of decline in FEV1? Am J Respir Crit Care Med 2000; 161: A531.

7 O'Hara P, Grill J, Rigdon MA, Connett JE, Lauger GA, Johnston JJ, for the Lung Health Study Research Group. Design and results of the initial intervention program for the Lung Health Study. Prev Med 1993; 22: 304-315.

8 O'Connor G, Sparrow D, Taylor D, Segal M, Weiss S. Analysis of dose-response curves to methacholine. Am Rev Respir Dis 1987; 136: 1412-1417.

9 Frost C, Fullerton FM, Stephen AM, et al. The tar reduction study: randomised trial of the effect of cigarette tar yield reduction on compensatory smoking. Thorax 1995; 50: 1038-1043.

10 Fagerstrom KO, Tejding R, Westin A, Lunell E. Aiding reduction of smoking with nicotine replacement medications: hope for the recalcitrant smoker? Tob Control 1997; 6: 311-316.

11 Hughes JR. Reduced smoking: an introduction and review of the evidence. Addiction 2000; 95: Suppl. 1, S3-S7.

12 Russell MA, Wilson C, Patel UA, Feyerabend C, Cole PV. Plasma nicotine levels after smoking cigarettes with high, medium, and low nicotine yields. BMJ 1975; 2: 414-416.

13 Benowitz NL, Jacob P 3rd. Nicotine and carbon monoxide intake from high- and low-yield cigarettes. Clin Pharmacol Ther 1984; 36: 265-270.

14 Benowitz NL, Jacob P 3rd, Yu L, Talcott R, Hall S, Jones RT. Reduced tar, nicotine and carbon monoxide exposure while smoking ultralow- but not low-yield cigarettes. JAMA 1986; 256: 241-246.

15 Zacny JP, Stitzer ML. Cigarette brand-switching: effects on smoke exposure and smoking behavior. J Pharmacol Exp Ther 1988; 246: 619-627.

16 Withey $\mathrm{CH}$, Papacosta $\mathrm{AO}$, Swan $\mathrm{AV}$, et al. Respiratory effects of lowering tar and nicotine levels of cigarettes smoked by young male middle tar smokers. II. Results of a randomised controlled trial. J Epidemiol Community Health 1992; 46: 281-285.

17 Rennard SI, Daughton D, Fujita J, et al. Short-term smoking reduction is associated with reduction in measures of lower respiratory tract inflammation in heavy smokers. Eur Respir J 1990; 3: 752-759.

18 Jimenez-Ruiz C, Solano S, Viteri SA, Ferrero MB, Torrecilla M, Mezquita MH. Harm reduction - a treatment approach for resistant smokers with tobacco-related symptoms. Respiration 2002; 69: 452-455.

19 Hughes JR, Lindgren PG, Connett JE, Nides MA. Smoking reduction in the Lung Health Study. Nicotine Tob Res 2004; 6: 275-280.

20 Wennike P, Danielsson T, Landfeldt B, Westin A, Tonnesen P. Smoking reduction promotes smoking cessation: results from a double blind, randomized, placebocontrolled trial of nicotine gum with 2-year follow-up. Addiction 2003; 98: 1395-1402.

21 Hurt RD, Croghan GA, Wolter TD, et al. Does smoking reduction result in reduction of biomarkers associated with harm? A pilot study using a nicotine inhaler. Nicotine Tob Res 2000; 2: 327-336.

22 Godtfredsen NS, Vestbo J, Osler M, Prescott E. Risk of hospital admission for COPD following smoking cessation and reduction: a Danish population study. Thorax 2002; 57: 967-972.

23 Eliasson B, Hjalmarson A, Kruse E, Landfeldt B, Westin A. Effect of smoking reduction and cessation on cardiovascular risk factors. Nicotine Tob Res 2001; 3: 249-255.

24 Hecht SS, Murphy SE, Carmella SG, et al. Effects of reduced cigarette smoking on the uptake of a tobacco-specific lung carcinogen. J Natl Cancer Inst 2004; 96: 107-115.

25 Tonnesen P. Smoking reduction for smokers not able or motivated to quit? Respiration 2002; 69: 475-478.

26 Fagerstrom K. Quit or die: nothing in between? Respiration 2002; 69: 387-388.

27 Falba T, Jofre-Bonet M, Busch S, Duchovny N, Sindelar J. Reduction of quantity smoked predicts future cessation among older smokers. Addiction 2004; 99: 93-102. 